\title{
An attempt to establish extinction-elicited aggression by withholding rewarding electrical stimulation of the brain'
}

\author{
RONALD GANDELMAN, ALAN B. \\ ASHTON, and JAY TROWILL, University \\ of Massachusetts, Amherst, Mass. 01002
}

An attempt was made to establish extinction-elicited aggression by withholding rewarding brain stimulation. Aggression, as measured by attack of one rat upon another, was not found in either $a$ food-deprived or a nondeprived group.

Intraspecies aggressive behavior has been elicited in rats (Thompson \& Bloom, 1966) and in pigeons (Azrin, Hutchinson, \& Hake, 1966) by discontinuing continuous positive reinforcement in the presence of another animal. Presumably, extinction-elicited aggression (EEA) is produced by the frustration accrued from the withholding of the reward (i.e., a frustration $\rightarrow$ aggression interpretation).

This experiment is an attempt to delineate the antecedents of EEA by employing intracranial electrical stimulation (ICR) as the reinforcer. Even when food-deprived, animals typically display more motivation to obtain ICR than they do to obtain food [e.g., rats will self-starve when given the opportunity to bar press for ICR during the daily 1 h feeding session (Routtenberg \& Lindy, 1965; see also Olds, 1958)]. Therefore, withholding ICR should produce a high degree of frustration. This most likely accounts for the rapid extinction of a response formerly rewarded with brain stimulation (Gandelman \& Trowill, 1968; Trowill, Panksepp, \& Gandelman, in press). If frustration is sufficient to establish EEA, aggression should be displayed by withholding ICR. However, since animals responding for conventional rewards are in most cases deprived, drive may be necessary for the occurrence of EEA. Thus, withholding of ICR in food-deprived animals may occasion the phenomenon.

\section{SUBJECTS}

Nine naive female albino rats, approximately 120 days old at the time of electrode implantation, were individually housed and maintained on ad lib water. All Ss were fed Purina Lab Chow pellets according to the schedules described below.

\section{SURGERY}

Under sodium nembutal anesthesia, one bipolar electrode was stereotaxically implanted with coordinates establishing placement in the medial forebrain bundle. The coordinates (Krieg, 1946) were $1.7 \mathrm{~mm}$ posterior to bregma, $1.4 \mathrm{~mm}$ lateral to the midline, and $8.2 \mathrm{~mm}$ below the level of the

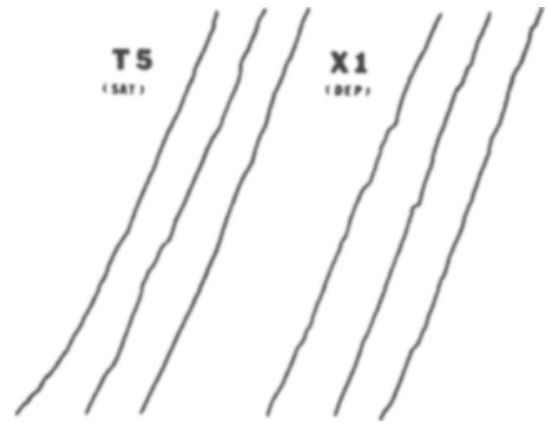

Fig. 1. Cumulative reinforcement records for typical nondeprived (F-5) and deprived (X-1) Ss prior to extinction.

skull. The incisor bar was set $3.1 \mathrm{~mm}$ above the intraoral line. Each pole of the electrode was $0.23 \mathrm{~mm}$ in diam and insulated except at the tip. The Ss were permitted 5 days of recovery before experimental manipulation began.

APPARATUS AND STIMULATION

Tests were run in an $8 \times 10 \times 16$ in. box. A Lehigh Valley Model 1352 permanent bar was mounted on one sidewall. Standard relay equipment permitted $S$ to receive electrical stimulation concurrent with a bar press.

Stimulation consisted of $0.5 \mathrm{sec}$ of 60 -cycle sine-wave current. The current was regulated by a micropot used as a voltage divider and was monitored by an ac microammeter in series with $S$.

PROCEDURE

On Day 6 following surgery $S$ was placed in the test box and given $0.5-\mathrm{sec}$ bursts of stimulation when it approached the bar (i.e., a shaping procedure) in increasing steps of $5 \mu \mathrm{A}$. Final intensities, ranging between 17 and $65 \mu \mathrm{A}$, were those which maintained stable levels of responding. The Ss were divided into two groups, one of which was maintained on ad lib food (Group SAT; $\mathrm{N}=5$ ) while members of the other group were fed $10 \mathrm{~g}$ of food per day throughout the entire experiment (Group DEP; $N=4$ ).

Following screening, 3 days of continuous reinforcement were given. Each $S$ was permitted 500 reinforced responses per day. During these sessions, and in the subsequent extinction session, a target rat, the same age and sex as the $S$, was placed in the test chamber. The same target rat was always paired with a particular S. On Day 4 Ss were given 250 reinforced responses followed by $15 \mathrm{~min}$ of extinction. The animals were observed by $\mathrm{E}$ during the extinction session, and aggressive behavior was recorded manually by closing the contacts of an event recorder. An aggressive response was defined as a striking or a biting movement directed at the target rat.

RESULTS AND DISCUSSION

Typical response records for $S s$ in Group SAT and in Group DEP are shown in Fig. 1. As can be seen, the animals responded rapidly and consistently for ICR. However, no aggressive behavior of any type was displayed during extinction by Ss of either group.

The results demonstrate that, within the conditions of this experiment, extinctionelicited aggression cannot be produced by the withholding of rewarding brain stimulation, a somewhat paradoxical finding in that ICR has been shown to be preferred over conventional rewards under their appropriate drive conditions. It appears, then, that frustration following the removal of ICR is not sufficient to produce EEA. In addition, unpublished data obtained in our laboratory show that aggression is not elicited in rats bar pressing to escape aversive brain stimulation when responding on the manipulandum no longer terminates the aversive stimulus, a situation which should also be highly frustrative.

The lack of aggression by members of Group DEP, a group which more closely approximates the conditions imposed upon animals responding for conventional rewards, implies that frustration coupled with an irrelevant drive (one not reduced by the goal object) is also not sufficient to produce EEA.

It may be that the necessary condition for the establishment of extinction-elicited aggression is the withholding of a deprivation-specific (i.e., deprivationreducing) reward. Therefore, the use of withholding rewarding brain stimulation would be precluded since its relation to deprivation is obscure if not nonexistent.

\section{REFERENCES}

AZRIN, N. H., HUTCHINSON, R. R., \& HAKE, D. F. Extinction-induced aggression. Joumal of the Experimental Analysis of Behavior, 1966, 9, 191-204.

GANDELMAN, R., \& TROWILL, J. The effects of chlordiazepoxide on ESB-reinforced behavior and subsequent extinction. Journal of Comparative \& Physiological Psychology, 1968, 66, 753-755.

KRIEG, W. J. Accurate placement of minute lesions in the brain of the albino rat. Quarterly Bulletin of the Northwestern University Medical School, 1946, 20, 199-208.

OLDS, J. Self-stimulation of the brain. Science, $1958,127,315-324$.

ROUTTENBERG, A., \& LINDY, J. Effects of the 
availability of rewarding septal and hypothalamic stimulation of bar-pressing for food under conditions of deprivation. Journal of Comparative \& Physiological Psychology,1965, 60, 158-161.

THOMPSON, T., \& BLOOM, W. Aggressive behavior and extinction-induced response rate increase. Psychonomic Science, 1966, 5, 335-336.

\section{Effects of the marihuana homologue, pyrahexyl, on a conditioned emotional response}

\author{
ERNEST L. ABEL, University of Toronto, \\ Toronto, Ont., Canada
}

A single injection into adult male rats of the marihuana homologue, pyrahexyl, disrupted the suppressive effect in a CER situation of a stimulus previously paired with shock. The latency to resume the operant in the pyrahexyl-injected $S$ s was one-half that shown by control animals. Three possible explanations for the effect are discussed.

Early research dealing with marihuanatype substances was hampered by the fact that material of fixed and known strength could not be obtained. This difficulty was overcome when Adams, Loewe, Jelinek, \& Wolff (1941) succeeded in isolating tetrahydrocannabinol as the active ingredient in marihuana (cannabis sativa). Once isolated, synthetic tetrahydrocannabinols could be prepared and one of the many derivatives thus produced was pyrahexyl (synhexyl). Although it has been available since 1943 (Adams, Haefenist, \& Loewe, 1943), there has been a paucity of research using this substance, and what research there is suffers from a grievous lack of experimental control. For some odd reason, experiments dealing with the behavioral effects of tetrahydrocannabinol compounds have been meagre, and this is puzzling since there appears to be considerable interest in marihuana-type substances (see reviews by Solomon, 1967, and Andrews \& Vinenoog, 1968). The work described herein is a study of the effects of pyrahexyl, one of the marihuana homologues, on a conditioned emotional response (CER).
TROWILL, J. A., PANKSEPP, J., \& GANDELMAN, R. An incentive model of rewarding brain stimulation. Psychological Review, in press.
NOTE

1. This study was supported by USPHS Grant MH13155-02 awarded to Jay Trowill impressive difference in the mean latency to resume bar pressing in the one-trial extinction test. Mean latency for the pyrahexyl group $(\mathrm{N}=14)$ was $28 \mathrm{~min}$ $42 \mathrm{sec}$, while the control group $(\mathrm{N}=14) \mathrm{had}$ a mean latency of $53 \mathrm{~min} 53 \mathrm{sec}$. This difference is highly significant $(U=16$, $\mathrm{p}<.001)$ and is akin to that reported by Boyd, Hutchinson, Gardner, \& Meritt (1963). These investigators found that MOP, a methyl-octyl tetrahydrocannabinol derivative likewise disrupts the suppressive effects of a CS in the CER situation.

The possible sources accounting for the disruption of the CER are: (1) general activation of behavior, (2) interference with the inhibitory mechanism responsible for suppression, and (3) anxiety reduction. The first alternative is unlikely since Abel and Schiff 1 have found that pyrahexyl-injected animals are less active, not more active, than control animals in an open field. As to the second possibility, McGlothlin (1965) has noted that among humans there tends to be a reduction in social inhibitions following the use of marihuana, but this may be the result of increased suggestibility while under the influence of cannabis. With regard to the third hypothesis, there tends to be somewhat contradictory results in the human research: Pond (1948) reported that pyrahexyl induced a state of apprehension in his Ss, whereas Stockings (1947) noted a feeling of euphoria connected with the drug. The data from this experiment tends to support Stockings' findings; however, the final interpretation must await further experimentation.

REFERENCES

ADAMS, R., LOEWE, S., JELINEK, C., \& WOLFF, H. Tetrahydrocannabinol homologs with marihuana activity. Journal of the American Chemical Society, 1941, 63, 1971-1976.

ADAMS, R., HAEFENIST, M., \& LOEWE, S. NeW analogs of tetrahydrocannabinol. Journal of the American Chemical Society, 1943, 71, 1624-1628.

ANDREWS, $\mathrm{G}$, \& VINENOOG, $\mathrm{S}$. (Eds.), The book of grass. New York: Grove Press, 1968.

BOYD, E. S., HUTCHINSON, E. D., GARDNER, L. C., \& MERITT, D. A. Effects of tetrahydrocannabinols and other drugs on operant behavior in rats. Archives Internationales de Pharmacodynamie et de Thérapie, $1963,144,533-554$.

McGLOTHLIN, W. H. Cannabis: A reference. In D. Solomon (Ed.), The marihuana papers. New York: Signet, 1968.

POND, D. A. Psychological effects in depressive patients of the marihuana homologue synhexyl. Journal of Neurology, Neuro-Surgery, \& Neuropsy chiatry, 1948, 11, 271-279.

SOLOMON, D. (Ed.), The marihuana papers. New York: Signet, 1968.

STOCKINGS, G. T. A new euphoriant for depressive mental states. British Medical Joumal, 1948, 1,918-922. NOTE

\section{RESULTS AND DISCUSSION}

A Mann-Whitney " $U$ " test revealed no differences between groups in the rate of responding during the $6 \mathrm{~min}$ prior to the onset of the CS. However, there was an
1. Abel, E. L., \& Schiff, B. B. Unpublished observations.

2. This research was supported by Grant No. NRC APB 149. 